\title{
Measurement and Prediction of Smoke Deposition from a Fire against a Wall
}

\author{
SIAMAK RIAHI ${ }^{1}$, and CRAIG BEYLER ${ }^{2}$ \\ ${ }^{1}$ Department of Civil and Environmental Engineering \\ The George Washington University \\ The Academic Center, $80122^{\text {nd }}$ Street, NW, Washington DC, 20052 USA \\ ${ }^{2}$ Hughes Associates \\ Fire Science and Engineering \\ 3610 Commerce Drive, Suite 817, Baltimore, MD 21227 USA
}

\begin{abstract}
Smoke deposition from different fuels and fire sizes to a vertical gypsum wall was studied using gravimetric measurements and a newly developed optical method. Optical properties of the deposited smoke were deduced from the gravimetric and optical measurements. Based on the new optical method, a photographic method was developed and used to quantify the smoke patterns on a wall adjacent to the fire source. The method is suitable for use in fire research and fire scene documentation. A thermophoretic smoke deposition model was extended and validated, using the experimental results from this work. The model can be used to predict smoke deposition rates and patterns due to thermophoresis.
\end{abstract}

KEYWORDS: smoke, smoke deposition, thermophoresis, wall fires.

\section{NOMENCLATURE LISTING}

$\begin{array}{ll}C_{s} & \text { smoke concentration }\left(\mathrm{kg} / \mathrm{m}^{3}\right) \\ d T / d x & \text { temperature gradient }\left({ }^{\circ} \mathrm{C} / \mathrm{m}\right) \\ f 1 & \text { filter 1 locations } \\ h & \text { convective heat transfer coefficient }\left(\mathrm{kW} / \mathrm{m}^{2}\right) \\ k & \text { thermal conductivity }(\mathrm{W} / \mathrm{m} \cdot \mathrm{K}) \\ m^{\prime \prime} & \text { mass per unit area }\left(\mathrm{g} / \mathrm{m}^{2}\right) \\ \dot{q}^{\prime \prime} & \text { heat flux }\left(\mathrm{kW} / \mathrm{m}^{2}\right) \\ T & \text { temperature }(\mathrm{K}) \\ V_{t h} & \text { thermophoretic velocity }(\mathrm{m} / \mathrm{s}) \\ y_{C O 2} & \text { carbon dioxide yield }(\mathrm{g} / \mathrm{g}) \\ y_{\text {soot }} & \text { smoke yield }(\mathrm{g} / \mathrm{g})\end{array}$

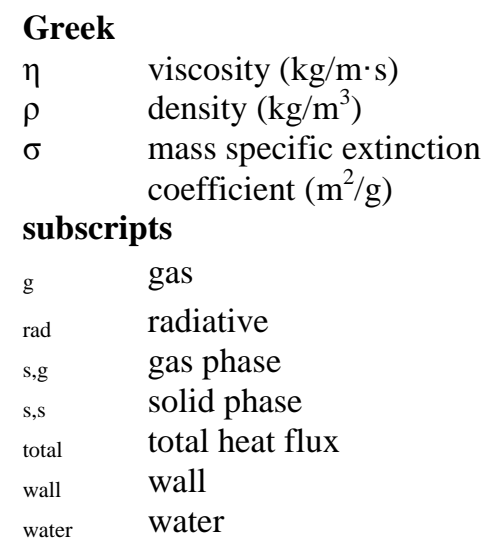

\section{INTRODUCTION}

Smoke deposition is the process in which smoke particles collect on a surface. Five smoke deposition mechanisms have been identified by Butler and Mulholland [1]; thermophoresis, diffusion, sedimentation, inertial impaction, and turbulent diffusion. Of these thermophoresis is the primary smoke deposition mechanism in fire. Thermophoresis is the movement of small particles in a temperature gradient from high to low temperature regions. Smoke deposited on surfaces is the greatest source of fire damage in fires. Commonly, direct fire damage may be confined to a fuel package with water damage limited to the room of origin, while smoke damage occurs throughout the structure. In addition, deposition of smoke on surfaces slows the operation of smoke alarms. Finally, smoke deposition patterns are central to the investigation of fires, though a firm scientific basis for the patterns has never been elucidated. While smoke deposition is of critical significance to property damage, smoke alarm activation, and forensic analysis of fire, little work has been done to understand and quantitate smoke deposition due to fires.

\section{LITERATURE REVIEW}

Most of the research related to smoke is focused on smoke dispersion and obscuration in the gas phase [2]. The effect of smoke on visibility is the primary concern [3]. Butler and Mulholland studied the 
characteristics of aerosols and evaluated the potential importance of different smoke deposition mechanisms in fire [1]. They concluded that thermophoresis is the most important smoke deposition mechanism in fire environments. Work on smoke deposition has been limited and focused on damage to electronic components by acid gases produced by burning PVC and other halogen containing polymers [46], rather than on particulates that dominate in all fires.

Smoke deposition based on thermophoresis was studied by Ciro et al. [7] to measure the smoke concentration within a pool fire. They measured the smoke deposition on a cold rod placed in the pool fire and deduced the smoke concentration using a thermophoretic model. Smoke deposition was sufficiently great that the smoke layer thickness could be measured directly. In most cases of interest in real fires the smoke deposition thickness is small and its thickness can not be measured directly.

There have been several investigations in recent years that indicated that smoke deposition is an important factor in the prediction of smoke densities. Gottuk et al. [8] showed that the smoke concentrations predicted by FDS at the smoke alarms in a corridor apparatus was 2-5 times greater than the measurements. They attributed the discrepancy to smoke deposition and demonstrated through recovery of deposited smoke after the test that approximately $30-40 \%$ of the smoke produced by the fire was deposited in the impact region alone. Hamins et al. [9] performed highly instrumented and carefully conducted full-scale compartment fires for use in validation and verification of various fire models including FDS. McGrattan [10] had excellent success in modelling these tests using FDS, except for predicted smoke concentrations that were up to five times greater than the measured concentrations. Notably, Hamins measured the total heat loss to the compartment boundaries and found that a very large fraction of the heat was lost to the boundaries in these tests. This is suggestive of thermophoretic deposition. Floyd [11] developed thermophoretic and turbulent diffusion smoke deposition models within FDS and performed trial calculations of these experiments and achieved better agreement with the data, though additional work needed to be done on the models. Cohan [12] simulated two of the Hamins et al. [9] NRC tests and the Gottuk [8] corridor tests using FDS 5.5.1 with smoke deposition and found better results for well-ventilated fires than closed compartment conditions. All these recent works indicate that smoke deposition has long been ignored as a significant sink for smoke in compartment fires.

Of course, smoke deposition patterns have long been used by the fire investigation community as a forensic tool [13], though there has been no work to demonstrate the scientific basis of smoke patterns in fire investigations. In order to remedy this situation, work has been undertaken to provide field documentation methodologies as well as a scientific basis for smoke pattern analysis in forensic investigations of fire. As part of this effort Riahi et al. [14-17] developed and used a new optical method to measure the smoke deposition onto wall mounted glass paper filters from a hot layer. The results showed that the method can be used as a successful tool for smoke deposition measurements and analysis in compartment fires. This work continues the development of the methods and bases.

\section{EXPERIMENTAL SET-UP}

The test wall consisted of a gypsum board wall (which was made in US) $(1.2 \mathrm{~m} \times 2.4 \mathrm{~m} \times 0.0127 \mathrm{~m}$ ). Gypsum board is the common material which is being used as the interior finish in buildings. The gypsum board was standard $0.5 "(0.128 \mathrm{~m})$ thick board with Kraft paper facing. Three different pan/sample sizes were used for the wall tests and for each test filter locations were different. The pan sizes $(4,8$ and 12 in. square, $0.1,0.2$ and $0.3 \mathrm{~m}$ ) were selected to include both laminar and turbulent flow regimes. Mass loss rate for the fuel was measured using a balance with capacity of $1000 \mathrm{~g}$ and $0.1 \mathrm{~g}$ resolution. Polymethylmethacrylate (PMMA), polypropylene (PP), acrylonitrile butadiene styrene (ABS), and gasoline were burned next to the gypsum wall.

Glass paper filters ( $9 \mathrm{~cm}$ diameter) are used to collect smoke at two locations. Grade G6 Fischer brand glass filters were used as the smoke collection medium. These filters do not readily absorb water, are not friable, and can withstand temperatures up to $600{ }^{\circ} \mathrm{C}$. Ceramic paper filters which can withstand $1000{ }^{\circ} \mathrm{C}$ were tried, but they were friable and soot loaded filters often weighed less than the original clean filter due to ceramic fiber losses. The diameter of the glass filters was $90 \mathrm{~mm}$ and their thickness was $0.32 \mathrm{~mm}$. Because of their white color, it is easy to measure the surface optical density after exposure to smoke. The glass paper filters location changed based on the fire size. Filters were mounted at a location such that they are outside the flame zone. Table 1 shows the filter locations for all three different pan sizes. 
Table 1. Filter locations for wall filters.

\begin{tabular}{|c|c|c|c|}
\hline \multicolumn{1}{|c|}{ Pan size } & Flame & Low filter location $(\mathbf{m})$ & High filter location $(\mathbf{m})$ \\
\hline $4^{\prime \prime} \times 4^{\prime \prime} \sim(0.1 \mathrm{~m} \times 0.1 \mathrm{~m})$ & Laminar & 0.9 & 1.2 \\
\hline $8^{\prime \prime} \times 8^{\prime \prime} \sim(0.2 \mathrm{~m} \times 0.2 \mathrm{~m})$ & Turbulent & 1.2 & 1.5 \\
\hline $12^{\prime \prime} \times 12^{\prime \prime} \sim(0.3 \mathrm{~m} \times 0.3 \mathrm{~m})$ & Turbulent & 1.5 & 1.8 \\
\hline
\end{tabular}

The filters were mounted on the gypsum wall using 8 small headed straight pins (10 mm long) around the circumference of the filter. These pins kept the filters in their location and flush to the wall to avoid the smoke deposition beneath the filters and to maintain good thermal contact. Schmidt-Boelter total heat flux gauges and radiometers were installed next to each glass filter $(2 \mathrm{~cm}$ from the center line as shown in Fig. 1). Gas and wall temperatures were measured by using 30-gauge, bare bead, Type-K thermocouples. Thermocouples were installed at the same elevation as the filter and they were located on the centerline of the gypsum wall. The gas thermocouple was $18 \mathrm{~mm}$ away from the wall for the low location and $28 \mathrm{~mm}$ away from the wall for the high locations. These values were measured after running exploratory tests to determine the gas thermocouple location outside the viscous sublayer by using a gas sand burner and changing the fire size from $3.0 \mathrm{~kW}$ to $35.0 \mathrm{~kW}$. The thermocouple location was varied between $5 \mathrm{~mm}$ and $35 \mathrm{~mm}$ from the wall in order to find the location outside the sublayer where the temperature reached its maximum value. Due to small path length, using a laser and detector were not feasible as a smoke concentration measurement method. Therefore, smoke concentrations at both low and high locations were determined by measuring the combustion products concentration and relating these concentrations to smoke concentration as is described subsequently.

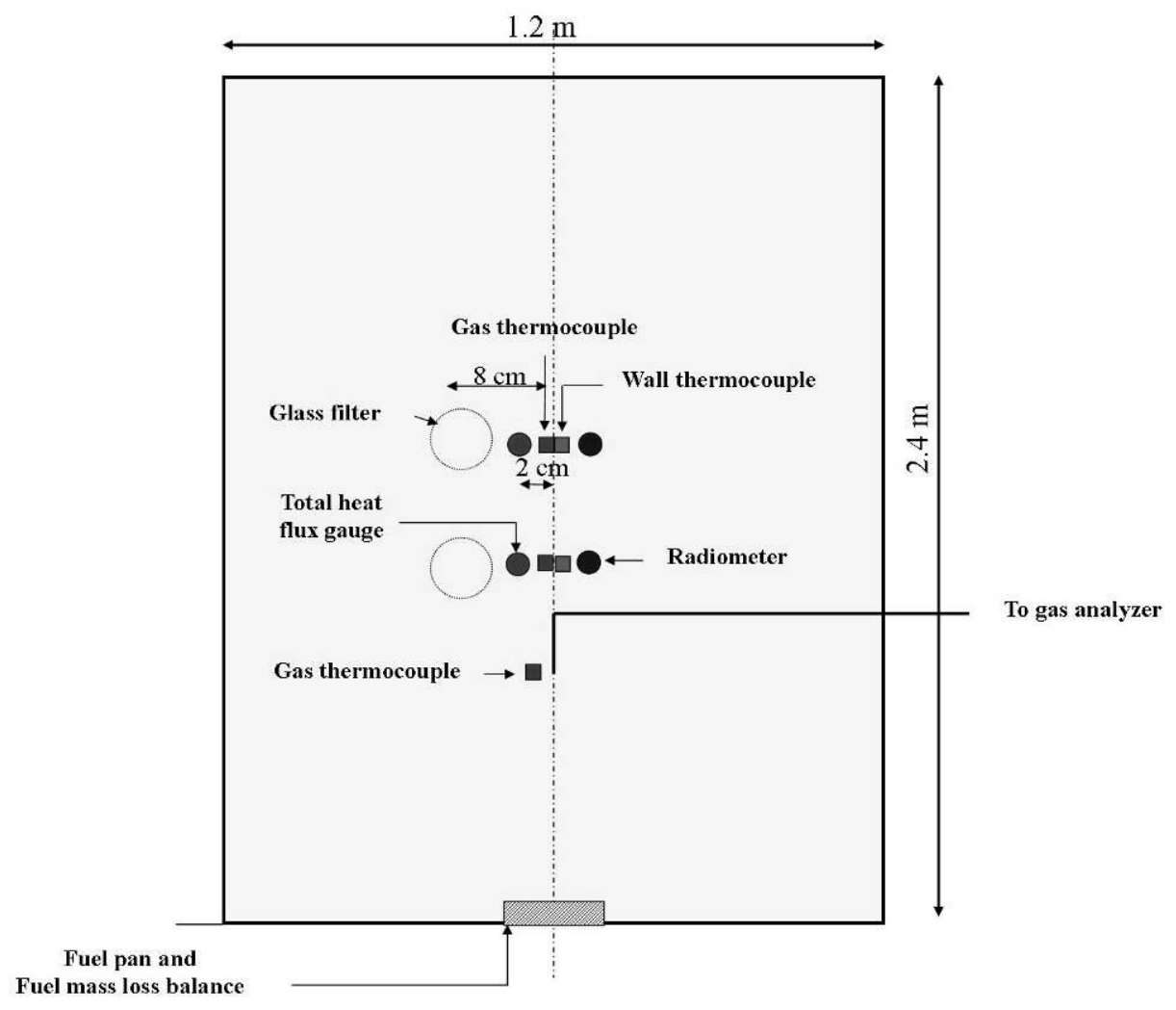

Fig. 1. Wall test apparatus front view (not to scale). 

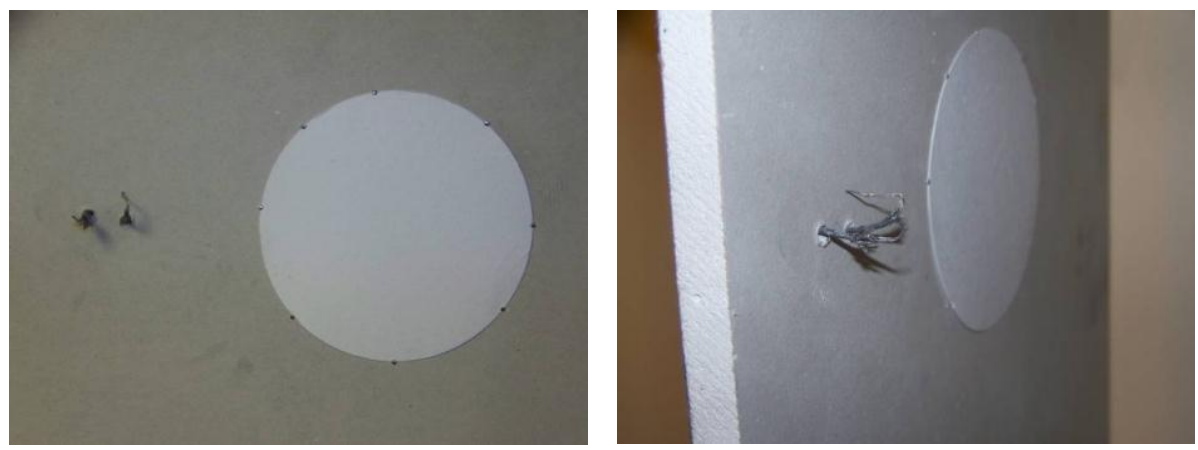

Fig. 2. Front and side view of gas and wall thermocouples adjacent to the glass filter. The pin system used to secure the filter is also shown.

Measurement of $\mathrm{O}_{2}, \mathrm{CO}_{2}$, and $\mathrm{CO}$ concentrations and temperature were made at the location below the low filter location. The sampling location was $4 \mathrm{~cm}$ below the low filter location and $1.2 \mathrm{~cm}$ away from the wall for all the tests. Smoke concentration $\left(C_{s}\right)$ is calculated by the procedure as follows. Using conservation of energy between the sampling point and the low filter location, it has been assumed that the reduction in the smoke concentration from the gas measurement point is due solely to dilution and losses due to radiative and conductive losses are negligible. These conditions are applicable over short distances outside the visible flame. The average sampling temperatures were around $300{ }^{\circ} \mathrm{C}$ and the average temperatures at the low and high filter locations were $220^{\circ} \mathrm{C}$ and $150{ }^{\circ} \mathrm{C}$, respectively. The smoke mass concentration $\left(\mathrm{g} / \mathrm{m}^{3}\right)$ at the filter $j$ location is determined by:

$\left(C_{s}\right)_{f 1}=\left(\frac{T_{g f 1}}{T_{g_{1}}}\right)\left(\frac{y_{s o o t}}{y_{\mathrm{CO}_{2}}}\right)\left(Y_{\mathrm{CO}_{2}}\right)_{j} \rho_{\text {air }}$

The volume percentage was converted to mass fraction using an average molecular weight of 29. The smoke concentration is determined at the sampling location based upon the measured $\mathrm{CO}_{2}$ concentration and the $\mathrm{CO}_{2}$ and soot yields measured in the calorimeter hood for each fire source.

\section{TEST PROCEDURE}

Polymethylmethacrylate (PMMA), polypropylene (PP), acrylonitrile butadiene styrene (ABS), and gasoline were burned next to the gypsum wall to include a range of smoke yields. The fire size was changed by changing the pan/sample size. Wall tests were performed in three different fire sizes. 4" $\times 4$ " pan size, $8 " \times 8$ " pan size, and $12 " \times 12^{\prime \prime}$ pan size.

Gravimetric measurements were performed on the glass filters before and after each test with the high accuracy scale $(0.1 \mathrm{mg})$. The filters were recovered after each test and there was no measureable amount of water in the filters and the mass gain was due to smoke deposition on the filters. Experimental data was collected using a National Instruments data acquisition chassis. The National Instruments hardware was interfaced with Labview 8.1 data acquisition software. The data acquisition system was set to a sampling rate of $1 \mathrm{~Hz}$. Data collection was continued until the fuel sample was completely burned and all the properties were back to ambient conditions.

\section{GRAVIMETRIC AND OPTICAL DENSITY MEASUREMENTS}

After each test, glass filters were collected and measured gravimetrically and optically. The optical density method has been is developed in this work as a smoke deposition measurement tool. A gray scale digital image is an image in which the value of each pixel is a single sample that carries only intensity information. Images of this sort, also known as black and white, are composed exclusively of shades of gray, varying from black at the weakest intensity to white at the strongest [18]. The intensity of a pixel is expressed within a given range between a minimum and a maximum, inclusive. No matter what pixel depth is used, the binary representations assume that zero is black and the maximum value (255) is white, if not otherwise noted. 


\section{Scanner Optical Density Method}

The filter was scanned next to a Kodak gray scale shown in Fig. 3, using a Canon flat bed scanner. The Kodak gray scale was scanned every time the filters were scanned in order to calibrate the digital image based on the gray scale values. Open source software from National Institute of Health, Image J [19], was used for calibration and image analysis.

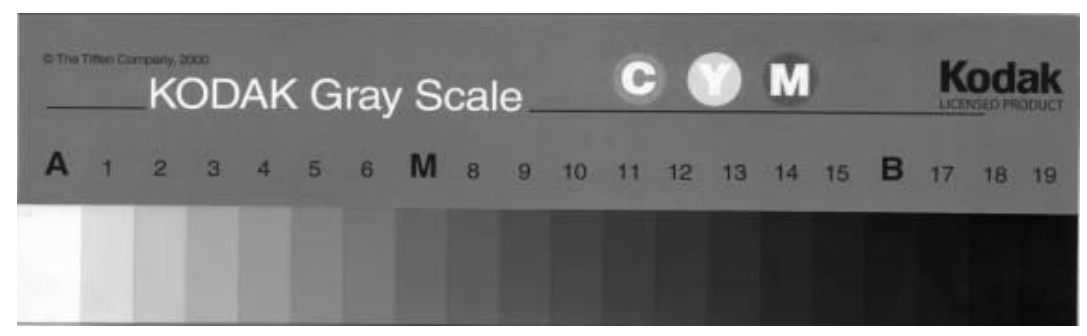

Fig. 3. Kodak gray scale.

The gray scale needs to be calibrated first and the gray scale values for every step is measured (From white to black, 20 steps).Then these gray scale numbers are related to the actual values given by the Kodak for the gray scale. For the shown gray scale, optical densities start from 0.05 to 1.95 with 0.10 increments. The next step for calibration is using the calibration function for the measured gray scale values. The "Rodbard" calibration function suggested by Image $\mathrm{J}$ for optical density was used. After calibration, optical density values were measured by using the Image $\mathbf{J}$ software to convert the gray scale values to optical density values based on the calibration function.

\section{Digital Photography Optical Density Method}

Scanning the filters can be used as a point measurement method in laboratory experiments but in the field for fire investigation, it is not feasible. For full wall measurements in the laboratory or in the field, a photographic method is required. Wall filters were photographed using two different digital cameras in the presence of the gray scale. The photographs were taken as filters were still on the wall and the gray scale was located next to the filers. The distance between the camera and the filter was $1.5 \mathrm{~m}$ and the camera's flash was used in addition to the normal lighting in the laboratory. The camera was used in point and shoot mode (automatic). The two cameras which were used in this work were; Kodak Easy Share Z7121S and Sony Cyber Shot PSC-P722.

\section{ANALYTICAL MODEL}

The thermophoretic smoke deposition velocity [20,21] is given by:

$V_{t h}=\frac{(0.55) \quad \eta}{\rho T}\left(\frac{d T}{d x}\right)$

The constant coefficient, 0.55 was derived from the kinetic theory calculations [22-26]. The following measurements were performed in order to calculate the temperature gradient at the surface. Total heat flux $\left(\dot{q}_{\text {total }}^{\prime \prime}\right)$ was measured by using a Schmidt-Boelter heat flux gauge and radiative heat flux $\left(\dot{q}_{\text {rad }}^{\prime \prime}\right)$ was measured by a Schmidt-Boelter radiometer. Convective heat flux $\left(\dot{q}_{c o n v}^{\prime \prime}\right)$ was calculated by difference between total and radiative heat fluxes.

The surface temperature on the Schmidt-Boelter heat flux gauge is close to the water temperature that was used to cool the heat flux gauge. The thermal gradient can be determined using conservation of energy at the surface. $k_{\text {air }}$, is the air conductivity at the film temperature. Also, the air density at the film temperature has been used. 
$\frac{d T}{d x}=\frac{h\left(T_{\text {gas }}-T_{\text {wall }}\right)}{k_{\text {air }}}=\frac{\frac{\dot{q}_{\text {total }}^{\prime \prime}-\dot{q}_{\text {rad }}^{\prime \prime}}{T_{\text {gas }}-T_{\text {water }}}\left(T_{\text {gas }}-T_{\text {wall }}\right)}{k_{\text {air }}}$

By employing temperature gradient derived in Eq. 4, thermophoretic velocity is determined as follows:

$V_{t h}=\frac{(0.55) \eta}{\rho T} \frac{\left(\dot{q}_{\text {total }}^{\prime \prime}-\dot{q}_{\text {rad }}^{\prime \prime}\right)\left(T_{\text {gas }}-T_{\text {wall }}\right)}{\left(T_{\text {gas }}-T_{\text {water }}\right) k_{\text {air }}}$

Smoke deposition based on thermophoresis is given by the integral over the test duration of the product of the time dependent thermophoretic velocity and smoke concentration.

$m^{\prime \prime}=\int_{0}^{t} V_{t h}(t) C_{s}(t) d t$

For each test the smoke deposition prediction was compared to the gravimetric measurements on the filters.

\section{RESULTS}

The results from the newly developed optical method were plotted against the gravimetric measurements of the smoke on the filter. Two optical methods were established in this work: the optical scanner method which was established by using the scanner and scanning the filters and photographic method. The solid phase mass specific extinction coefficient is the ratio between the optical density and the smoke mass density per unit area on the glass paper filter. Solid phase mass specific extinction coefficients were determined for PMMA, PP, gasoline, and ABS for three different pan sizes. Moreover, comparisons between the experimental data and the smoke deposition model based on thermophoresis were performed. Also smoke patterns on the gypsum wall based on digital photography was performed.

\section{Solid Phase Mass Specific Extinction Coefficient Using the Optical Scanner Method}

For all the tests, wall filters were collected from both locations and data were processed using the Matlab code. For each fuel and pan size, surface optical densities were plotted vs. the measured smoke deposited per unit area on the filter. By plotting the surface optical density vs. the measured smoke deposited per unit area on the filters for the PMMA, PP, and gasoline tests, the average solid phase mass specific extinction coefficient value $\left(\sigma_{s, s}\right)$ for these tests were determined. Solid phase mass specific extinction coefficient has the same units as gas phase mass specific extinction coefficient $\left(\mathrm{m}^{2} / \mathrm{g}\right)[2]$.

Figure 4 shows the solid phase mass specific extinction coefficient for PMMA, gasoline, and PP tests for the laminar 4" $\times 4$ " pan fires. The solid phase mass specific extinction coefficient for the laminar flames is $5.3 \mathrm{~m}^{2} / \mathrm{g}$, which is close to the values reported for the hood tests [2,3]. This shows although the hood tests were based on smoke deposition from a hot layer to a surface, the solid phase mass specific extinction coefficient values are very close because they both have the same flow regime (laminar). For ABS, the solid phase mass specific extinction coefficient values is $3.3 \mathrm{~m}^{2} / \mathrm{g}$. ABS is an aromatic fuel and it exhibits increased agglomerate sizes on the scans of the filter. Since the agglomerates from ABS tests are not spread uniformly on the filter's surface, they are not optically as efficient as other fuels. They increase the mass on the filters; however, the optical density of the filter does not change as much as the smoke mass density. This is the reason for lower solid phase mass specific coefficient on the wall filter from the ABS tests. 


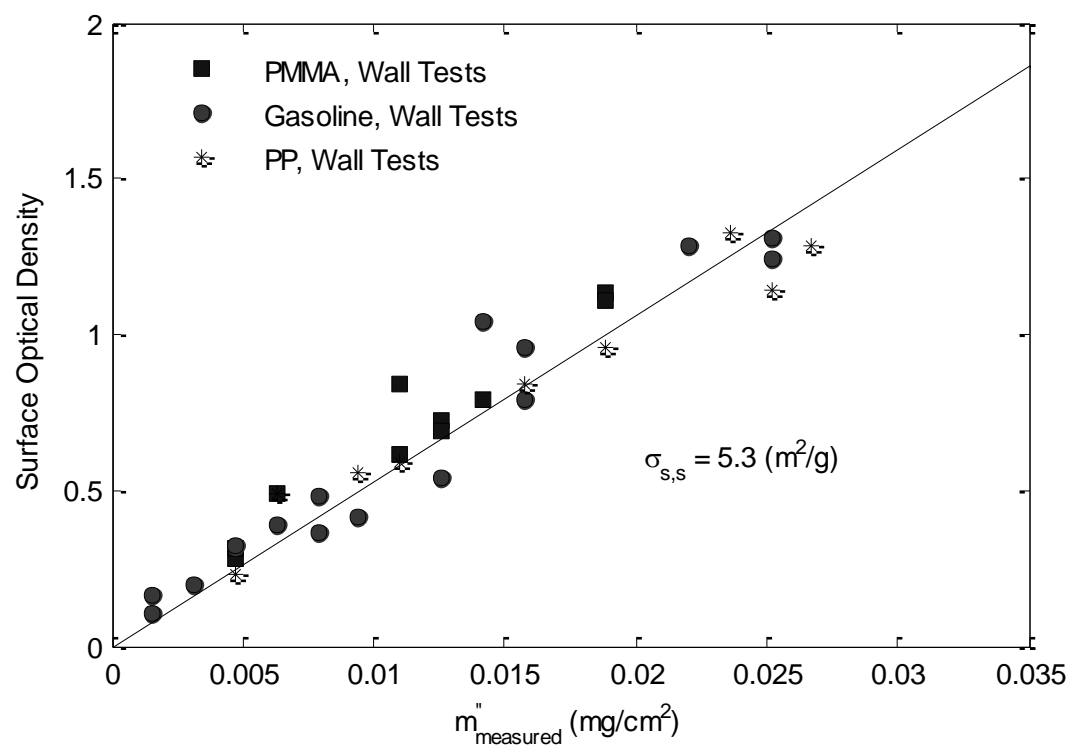

Fig. 4. $\sigma_{s, s}$ value for laminar 4" $\times 4 "$ pan size tests for PMMA, gasoline, and PP.

The solid phase mass specific extinction coefficient for the same fuels (PMMA, PP, gasoline) for the turbulent $8 " \times 8$ " and $12 " \times 12$ " pan fires were $69 \%$ and $77 \%$ of the values for laminar $4 " \times 4 "$ pan fires. Table 2 shows the solid phase mass specific extinction coefficient values for PMMA, gasoline, and PP tests. There are two different effects on the solid phase mass specific extinction coefficient that need to be considered. The first effect is due to the chemistry of the fuel via the smoke yield from the fuel. The higher the smoke yield, the lower the solid phase mass specific extinction coefficient. The second effect is due to the physics of the fire. The laminar fires increase the solid phase mass specific extinction coefficient over the turbulent fires.

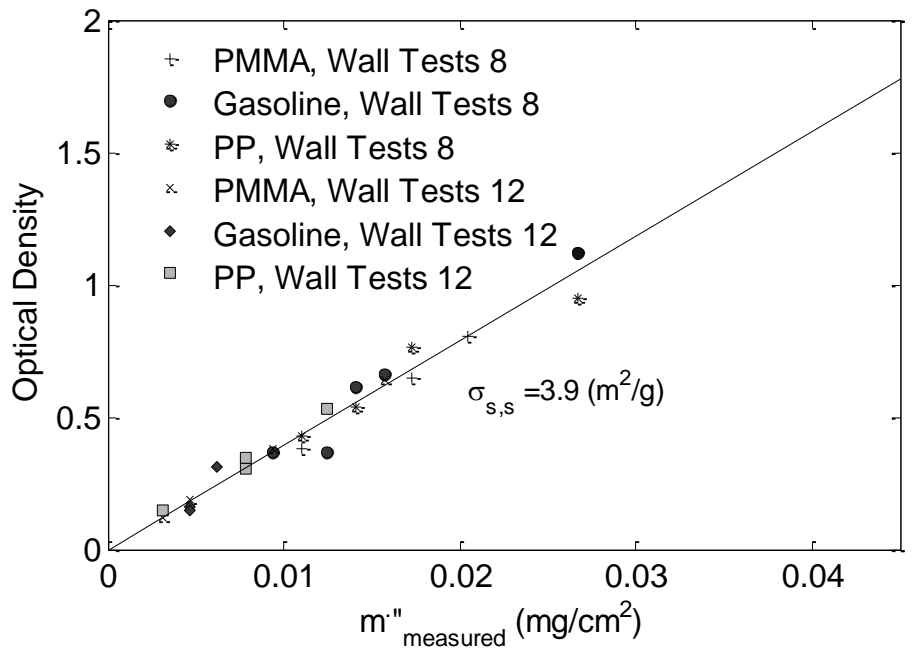

Fig. 5. $\sigma_{s, s}$ value for PMMA, gasoline, and PP for $8 " \times 8 "$ and $12 " \times 12 "$ pan sizes.

Table 2 shows the different solid phase mass specific extinction coefficient values for the wall test. 
Table 2. Solid phase mass specific extinction coefficient for different fuels and fire sizes.

\begin{tabular}{|c|c|c|}
\hline Pan size & $\begin{array}{c}\text { Solid phase mass specific extinction } \\
\text { coefficient } \\
\text { PMMA, PP, gasoline, } \mathbf{A B S}\left(\mathbf{m}^{\mathbf{2}} / \mathbf{g}\right)\end{array}$ & $\begin{array}{c}\text { Solid phase mass specific extinction } \\
\text { coefficient } \\
\text { ABS }\left(\mathbf{m}^{2} / \mathbf{g}\right)\end{array}$ \\
\hline $4^{\prime \prime} \times 4^{\prime \prime}$ & 5.3 & 3.3 \\
\hline $8^{\prime \prime} \times 8^{\prime \prime}$ & 3.7 & 1.9 \\
\hline $12^{\prime \prime} \times 12^{\prime \prime}$ & 4.1 & 1.7 \\
\hline
\end{tabular}

\section{Agglomerate Size Distribution and Solid Phase Mass Specific Extinction Coefficient}

The difference between the solid phase mass specific extinction coefficient values is due to the agglomerate size distribution on the filters. Data analysis was conducted on the wall filters with the similar optical density values from different tests. The number of agglomerates was plotted vs. agglomerate diameter for each filter. The agglomerate diameter size was calculated based on the pixel concept. Image $\mathbf{J}$ software identifies agglomerates within the size which can be specified in the software. The agglomerate size analysis along with the solid phase mass specific extinction coefficient results showed the evidence of correlations of agglomerate number density with soot yield. As the smoke yield increases the solid phase mass specific extinction coefficient decreases as shown in Fig. 6. The dominant smoke deposition mechanism for the experiments is thermophoresis. The smoke deposition for these experiments is dependent on the thermophoresis which is dependent on the temperature gradient and the smoke concentration. The surface texture does not have any effect on the smoke deposition; however the physical properties of the surface will change the temperature gradient. Based on the results from the tests, the smoke deposition did not vary between the filter and the wall.

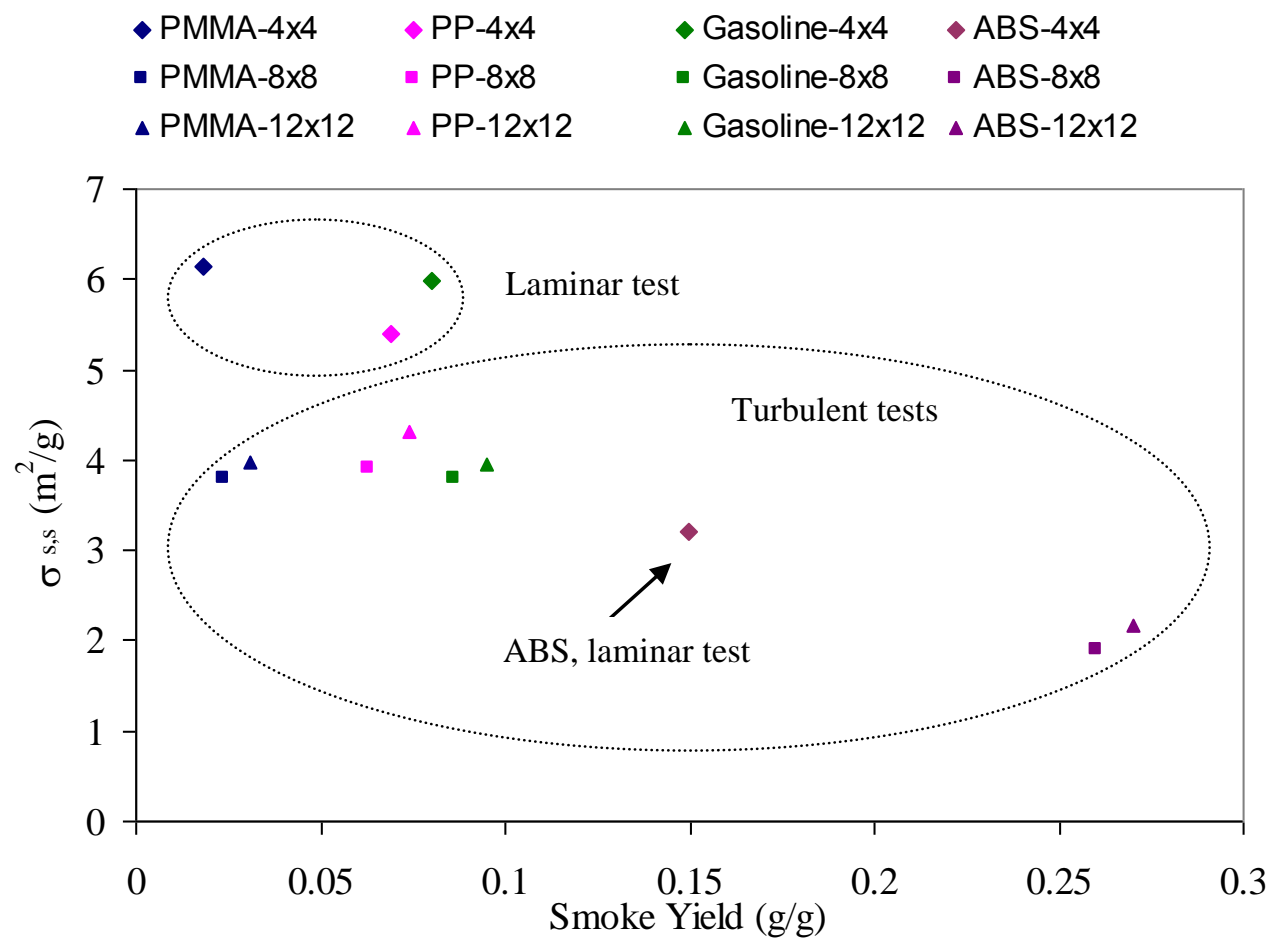

Fig. 6. Smoke yield and solid phase mass specific extinction coefficient variation for the wall tests.

\section{THERMOPHORETIC SMOKE DEPSITION MODEL VALIDATION}

Surface smoke mass density data for PMMA, gasoline, PP, and ABS were compared to the predictions of the thermophoresis model. Smoke deposited on each filter was measured gravimetrically and predicted using the thermophoretic model. Total heat flux, radiative heat flux, gas and wall temperature and optical 
density at location were used in the analytical model. Figure 7 shows the predicted thermophoretic deposition vs. measured (gravimetric) deposition for PMMA, PP, gasoline, and ABS for all three pan sizes. It shows that thermophoretic model predicts the smoke deposition for these fuels very well. This validates the thermophoretic model as an accurate model to predict smoke deposition onto walls from an adjacent fire.

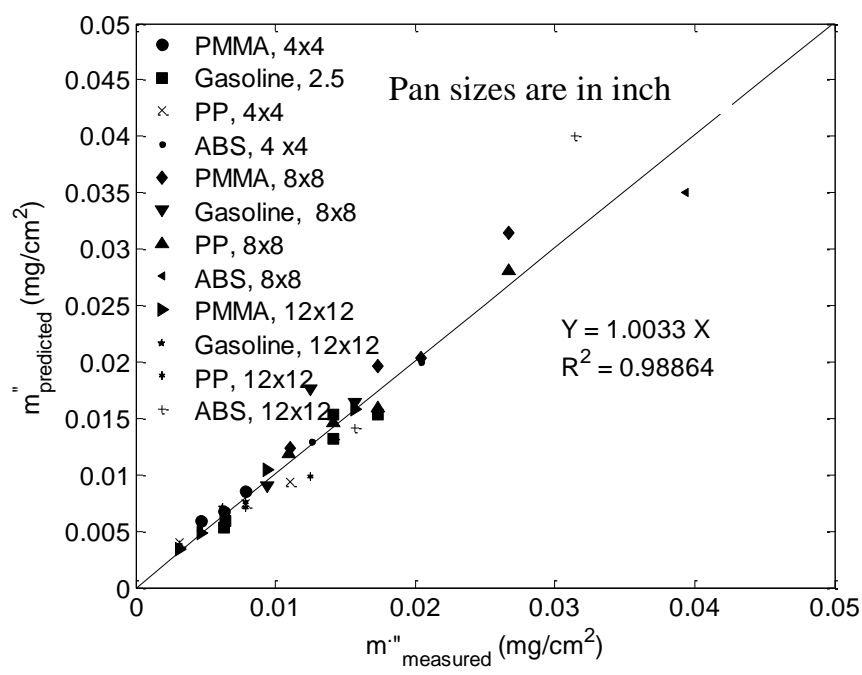

Fig. 7. Predicted thermophoretic smoke deposition vs. gravimetrically measured smoke deposition.

\section{WALL SMOKE PATTERNS}

Figure 8 shows that the determined optical density values on the glass filter papers are not strongly dependent on the digital camera which was used. Also the same wall filters were scanned with the flat bed scanner in the presence of the same gray scale. The optical properties of the filters were determined using the Image $\mathbf{J}$ software and the Rodbard calibration curve.
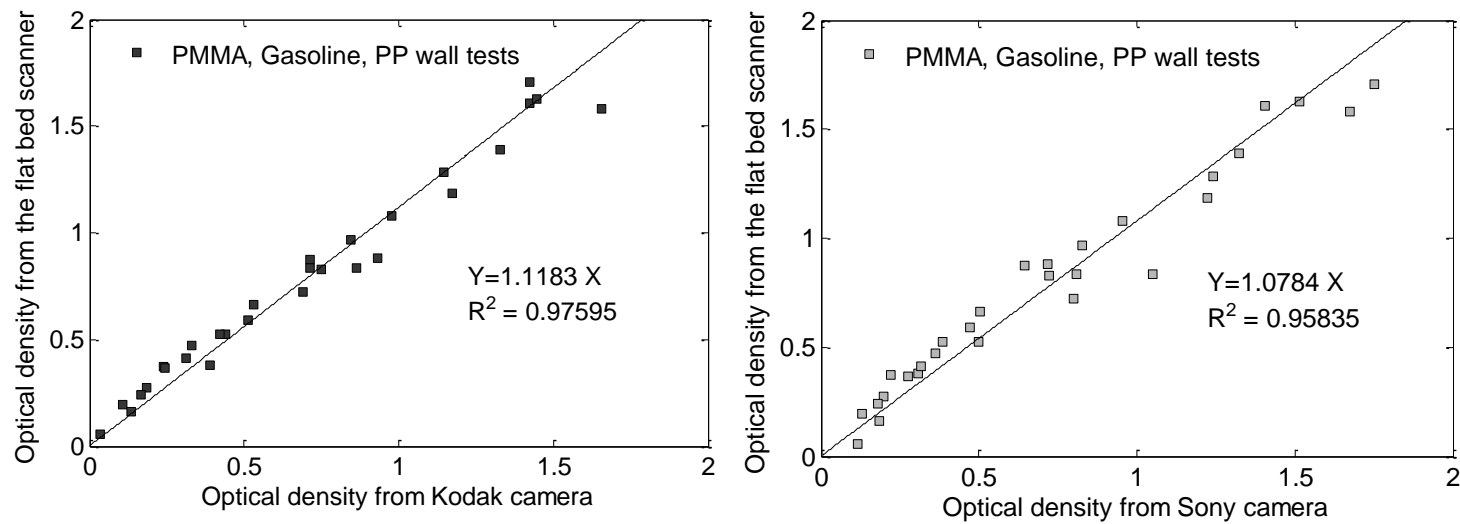

Fig. 8. Comparison between optical properties of the filters scanned with flat bed scanner and the digital pictures taken by the Kodak and Sony cameras.

The established photographic method was applied to the wall tests. The gypsum wall was exposed to smoke from PMMA, PP, gasoline, and ABS fuels with different test durations. After each test a digital photograph of the wall with a gray scale in the field of view was taken. The pictures were taken from $1.5 \mathrm{~m}$ distance and the resolution on the camera was set to 4 megapixels. The surface should not be over-exposed to the direct light with flash and automatic settings; otherwise the gray scale calibration would be inaccurate. All the digital pictures were processed using the Image $\mathbf{J}$ software. First step for processing the digital image from the wall test is to scale the image using the scale function in the Image $\mathbf{J}$ software. It provides the number of pixels $/ \mathrm{cm}$. The next step is to discretize the image into $1 \mathrm{~cm}^{2}$ squares, in which the optical 
properties will be measured. The results of analysis were combined to create a contour plot of the smoke deposition on the wall for comparison with the actual digital image. Since the process of measuring the optical properties of the $1 \mathrm{~cm}^{2}$ squares on the wall is a tedious procedure, a Matlab program was written specifically for this purpose and linked to the macro feature in the Image $\mathbf{J}$ software. The results for different grid size were compared and the $1 \mathrm{~cm}^{2}$ grid size gives the high resolution for the optical density contours. This makes the determination of the optical properties of the wall surface. The final step was to combine all the results and plot the optical density contours of the wall, and compare the contours to the digital photographic images. Figure 9 shows the comparison between the digital photographs from a gypsum wall vs. the optical density contours from the developed method. The clean burn area and the flame height are captured by the optical density contours. The digital image was processed by using established Matlab code with Image $\mathbf{J}$ software.
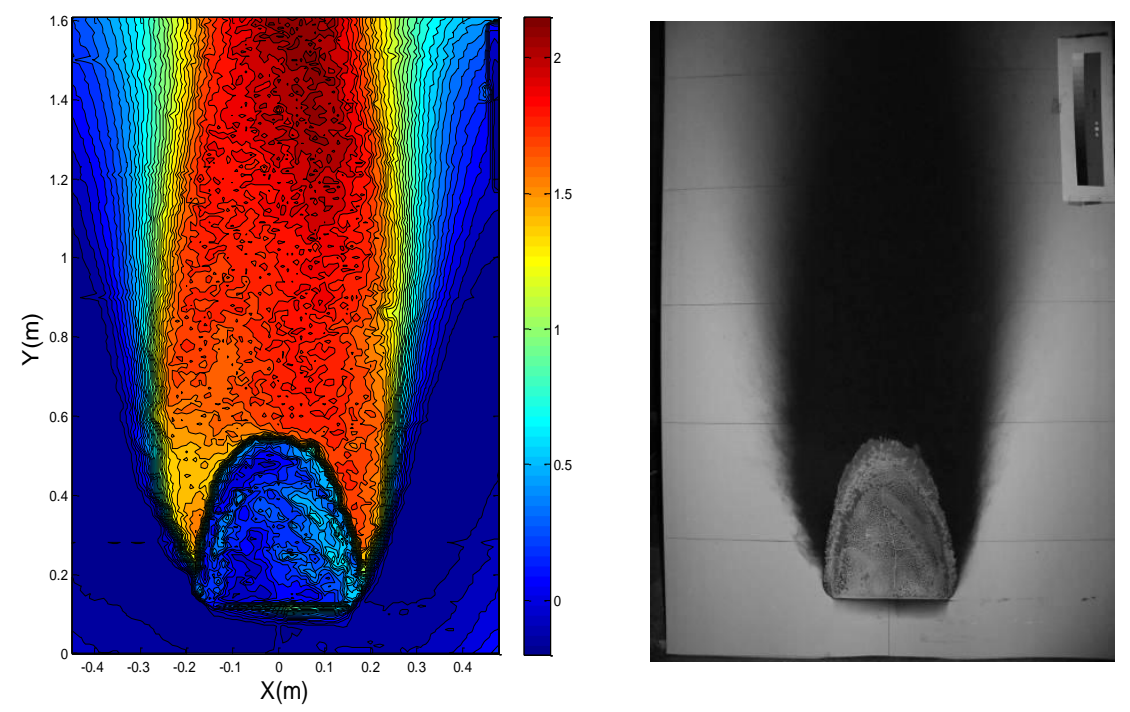

Fig. 9. Digital image vs. optical measurement method for a turbulent ABS test for 8". pan.

Different effects from the wall test were studied. The fire size effect, fuel effect, and test duration are very important factors which change the deposition based on the thermophoresis mechanism.
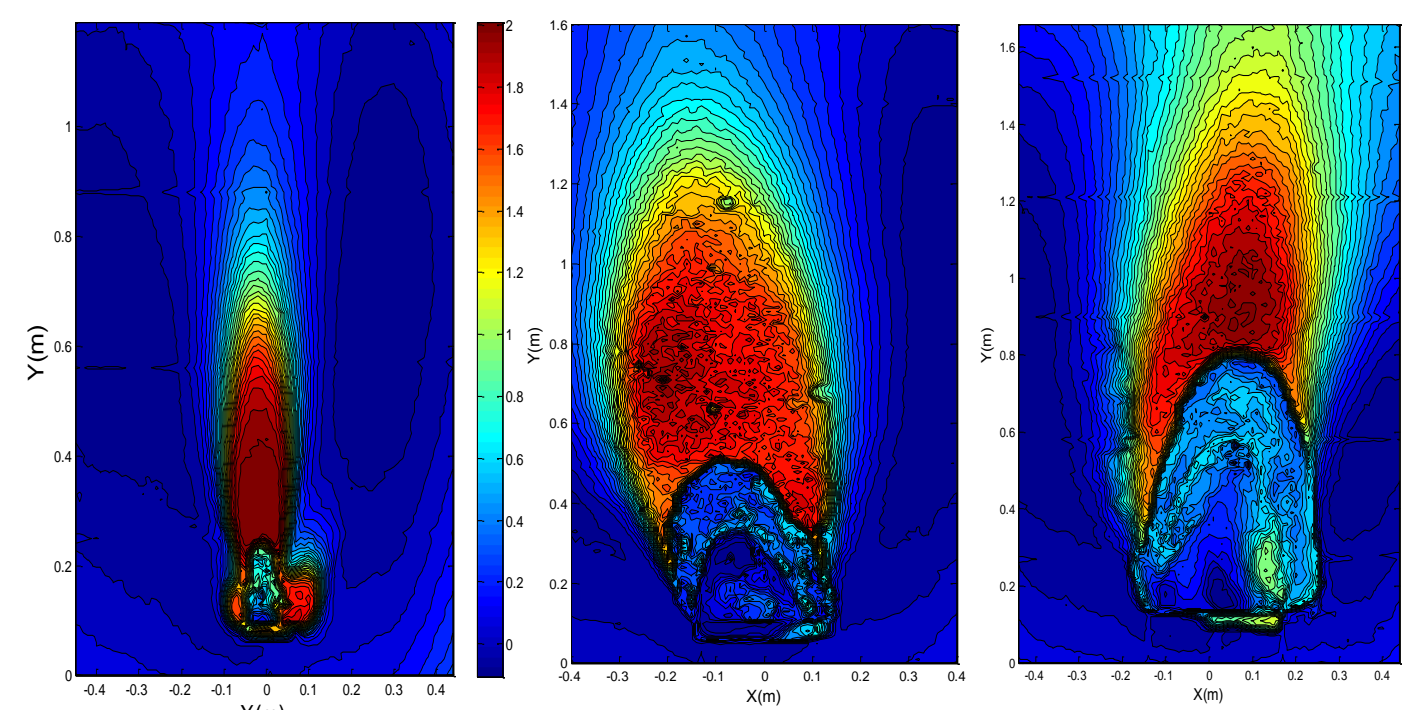

Fig. 10. Opth́cal density contours for $4 " \times 4 ", 8 " \times 8 "$, and $12 " \times 12 "$ pan size PMMA tests. 
Figure 10 shows the optical density contours for PMMA tests next to a gypsum wall. The fire size for the $4 " \times 4$ " pan size is $3.0 \mathrm{~kW}$ and equivalent pan diameter is $0.114 \mathrm{~m}$. The fire size and the equivalent pan diameter for the $8 " \times 8 "$ and $12 " \times 12 "$ pan sizes are $12.0 \mathrm{~kW}, 30.0 \mathrm{~kW}$ and $0.22 \mathrm{~m}, 0.33 \mathrm{~m}$, respectively. The test duration for the aforementioned tests were; $4400 \mathrm{~s}, 3000 \mathrm{~s}$, and $2700 \mathrm{~s}$. The clean burn area shows the flame height and can be used to determine the fire size. Also it showed that smoke deposition pattern on the gypsum wall will be larger for larger fires. Three different effects were studied for the pattern tests, the fire size effect, the fuel effect, and the test duration effect. The smoke pattern for larger fires is larger than the smaller fires. This effect has been shown in Fig. 10. For all the fire sizes for the PMMA tests, the optical density values on the center line were plotted vs. the non dimensional value $(z / L)$ where $z$ is the height for the location and $L$ is the turbulent mean flame height based upon the Heskestad flame height equation [27]. Figure 11 shows the optical density variation on the center line for three fire sizes for the PMMA test against the gypsum wall. Results show the surface optical density values distribution for laminar tests and turbulent tests are different. Note that for the turbulent flames that the clean zone extends to the Heskestad flame height.

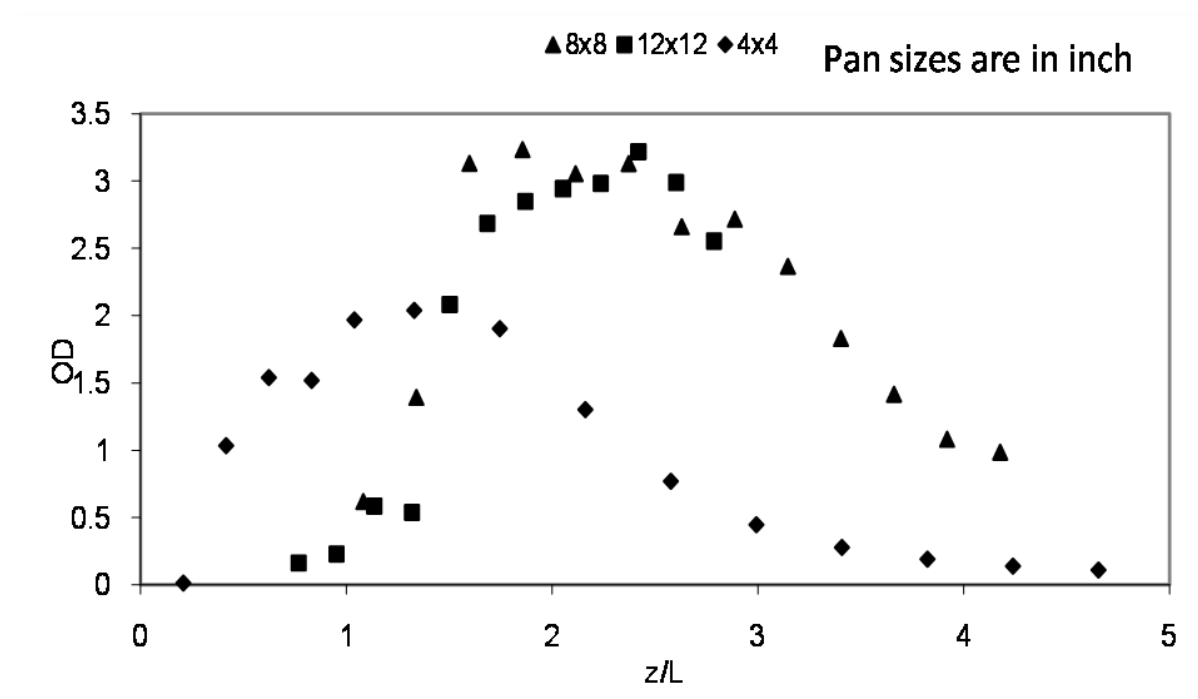

Fig. 11. Optical density variation for different PMMA fire sizes at different locations on the flame center line.

Figure 12 shows the effect of the fuel. These are results for $8 " \times 8$ " pan fires. One is for PP and the other is for ABS. ABS has higher smoke yield and higher optical density concentration is evident for ABS. The burring duration for PP was $850 \mathrm{~s}$ and the burning duration for ABS was $600 \mathrm{~s}$. Due to higher burning duration for PP, the clean burn area is slightly larger for PP fire. 


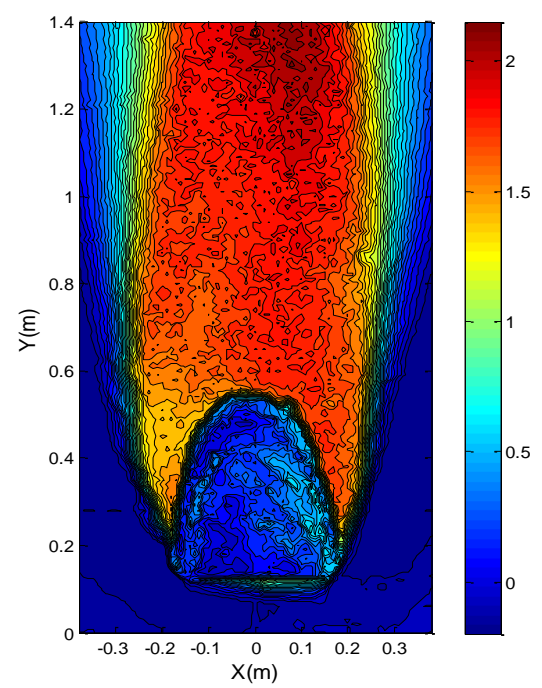

(a)

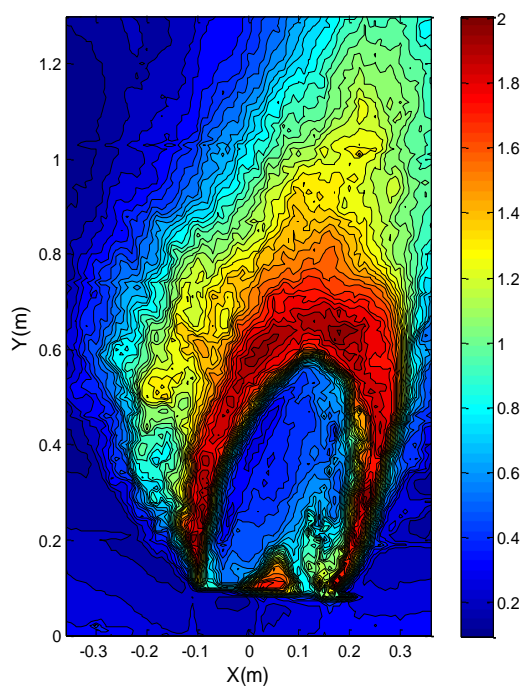

(b)

Fig. 12. Smoke patterns for $8 " \times 8 "$ pans: (a) PP test; (b) ABS test.

Fig. 13 shows the smoke pattern from a $12 " \times 12$ " pan for the gasoline test. One of them is a $440 \mathrm{~s}$ burn duration test and the other is a $700 \mathrm{~s}$ burn duration test. The smoke pattern shows that the longer burn duration, the larger the clean burn zone. Also, the longer the wall has been exposed to the smoke, the larger the smoke pattern is. The smoke deposition model as explained earlier is time dependent and the smoke patterns shown in Fig. 13 indicate the smoke deposits on the surface and as wall is heated further over time, the smoke burns off.

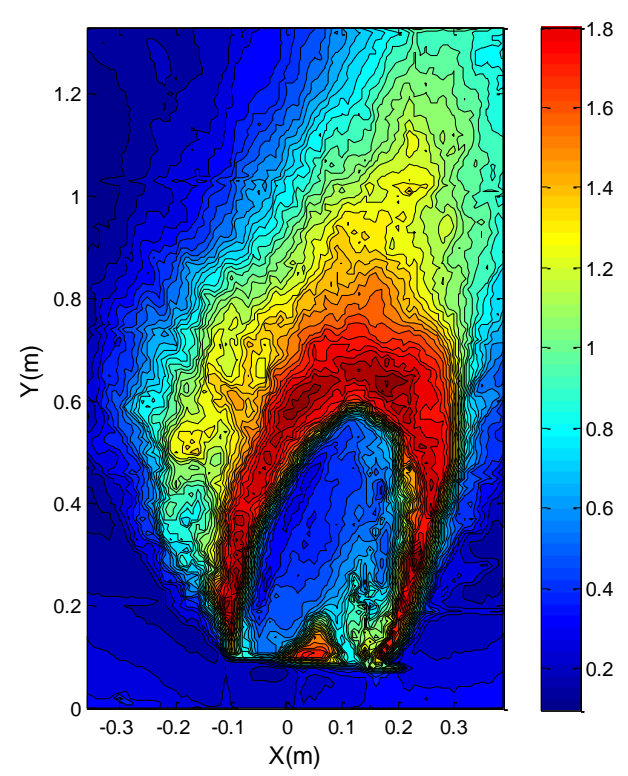

(a)

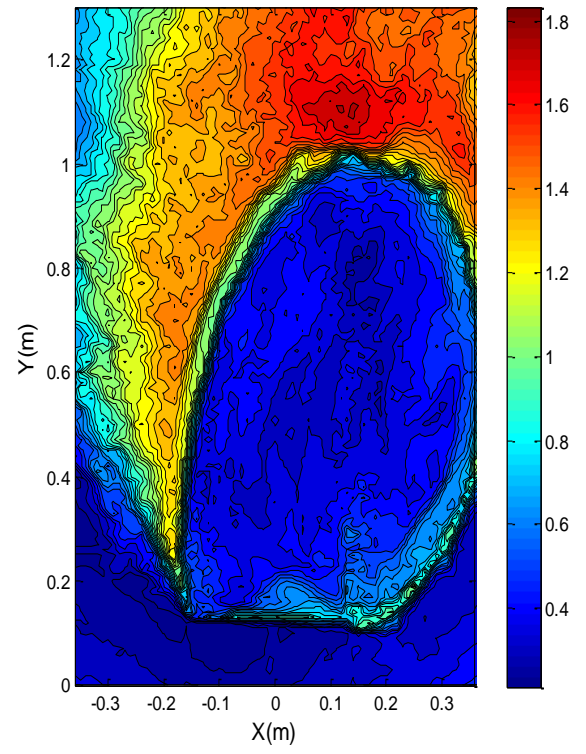

(b)

Fig. 13. Smoke pattern for 12" $\times 12 "$ pan gasoline tests: (a) $440 \mathrm{~s}$; (b) $700 \mathrm{~s}$.

\section{CONCLUSION}

Experimental methods for gravimetric and optical measurements of smoke deposition have been developed for use in fire research and field investigations. A thermophoretic smoke deposition model has been validated for use in fires against walls. Solid phase mass specific extinction coefficient $\left(\sigma_{s, s}\right)$ was determined 
for PMMA, PP, gasoline, and ABS tests for three different pan sizes. A direct relationship between the smoke yield and solid phase mass specific extinction coefficient was identified. These tests were laminar and turbulent and the relationship between the solid phase mass specific extinction coefficient and the flow regime in the tests was determined. Smoke pattern on the gypsum walls was determined for different fuels, fire size, and test duration.

\section{ACKNOWLEDGMENTS}

This project was supported by Award No. 2007-DN-BX-K236 awarded by the National Institute of Justice, Office of Justice Programs, US Department of Justice. The opinions, findings, and conclusions or recommendations expressed in this publication are those of the authors and do not necessarily reflect those of the Department of Justice.

\section{REFERENCES}

[1] Butler, K. and Mulholland, G., (2004) Generation and Transport of Smoke Components, Fire Technology 40(2): 149-176, http://dx.doi.org/10.1023/B:FIRE.0000016841.07530.64

[2] Mulholland, G. W., "Smoke Production and Properties," The SFPE Handbook of Fire Protection Engineering, National Fire Protection Association, Quincy, MA, 2002, pp. 258-268.

[3] Jin, T. and Yamada, T., (1989) Experimental Study of Human Behavior in Smoke Filled Corridors, Fire Safety Science 2: 511-519, http://dx.doi.org/10.3801/IAFSS.FSS.2-511

[4] Tewarson, A, "Smoke Contamination of Surfaces," Fire and Explosion Hazards Proceedings of the Fourth International Seminar, University of Ulster, 2004, pp. 333-343.

[5] Reagor, B., (1992) Smoke Corrosivity: Generation, Impact, Detection, and Protection, Journal of Fire Sciences 10(2): 169-179, http://dx.doi.org/10.1177/073490419201000206

[6] Tanaka, T., "Effects of Smoke on Functional Circuits," Sandia National Laboratories 1997.

[7] Ciro, W., Eddings, E., and Sarofim, A., (2006) Experimental and Numerical Investigation of Transient Soot Buildup on a Cylindrical Container Immersed in a Jet Fuel Pool Fire, Combustion Science and Technology 178(12): 2199-2218, http://dx.doi.org/10.1080/00102200600626108

[8] Gottuk, D., Mealy, C., and Floyd, J., (2009) Smoke Transport and FDS Validation, Fire Safety Science 9: 129-140, http://dx.doi.org/10.3801/IAFSS.FSS.9-129

[9] Hamins, A., Maranghides, A., Johnsson, E. L., Donnelly, M. K., Yang, J. C., Mulholland, G. W., Anleitner, R. L., "Report of Experimental Results for the International Fire Model Benchmarking and Validation Exercise \#3," National Institute of Standards and Technology, Gaithersburg, MD, 2005.

[10] McGrattan, K., "Verification \& Validation of Selected Fire Models for Nuclear Power Plant Applications," Nuclear Regulatory Commission, Report Volume 7: Fire Dynamics Simulator, NUREG-1824, Washington DC, 2007.

[11] Floyd, J., "Modeling soot deposition using large eddy simulation with a mixture fraction based framework," Interflam 2010, Interscience Communications, 2010.

[12] Cohan, B., "Verification and Validation of a Candidate Soot Deposition Model in Fire Dynamics Simulator Version 5.5.1," University of Maryland, College Park, MD, 2010.

[13] NFPA 921: Guide for Fire and Explosion Investigations, National Fire Protection Association, Quincy, MA, 2011.

[14] Riahi, S., Beyler, C. Hartman, J., Roddis, K., "Development of tools for smoke residue and deposition analysis," Proceedings of Fall Technical Meeting, Eastern States Sections of the Combustion Institute, University of Maryland, College Park, 2009.

[15] Riahi, S., Beyler, C., Hartman, J., "Measurement and prediction of smoke deposition in fires," Interflam 2010, Interscience Communications, 2010. 
[16] Riahi, S., Beyler, C., Hartman, J. Roddis, K., "New tools for smoke residue and deposition analysis", Journal of Fire Safety (submitted).

[17] Riahi, S., Beyler, C., "Development of tools for smoke residue and deposition analysis," National Institute of Justice, Washington DC, 2010.

[18] Johnson, S., On Digital Photography, O’Reilly, Italy, 2006.

[19] Ferreira, T., Rasband, W., The Image J User Guide 1.44, National Institute of Health, U.S.A, 2011.

[20] Talbot, L., Cheng, R., Schefer, R., and Willis, D., (2006) Thermophoresis of particles in a heated boundary layer, Journal of Fluid Mechanics 101(04): 737, http://dx.doi.org/10.1017/S0022112080001905.

[21] Waldmann, L., Schmitt, K., Aerosol Science, Academic Press, New York, 1966.

[22] Derjaguin, B., Storozhilovz, A., and Rabinovich, Y., (1966) Experimental verification of the theory of thermophoresis of aerosol particles, Journal of Colloid and Interface Science 21(1): 3558, http://dx.doi.org/10.1016/0095-8522(66)90079-1

[23] Brock, J., (1962) On the theory of thermal forces acting on aerosol particles, Journal of Colloid Science 17(8): 768-780, http://dx.doi.org/10.1016/0095-8522(62)90051-X

[24] Friedlander, S., Smoke, Dust, and Haze: Fundamentals of Aerosol Dynamics, Oxford University Press, New York, 2000.

[25] Derjaguin, B. and Yalamov, Y., (1965) Theory of thermophoresis of large aerosol particles, Journal of Colloid Science 20(6): 555-570, http://dx.doi.org/10.1016/0095-8522(65)90035-8

[26] Derjaguin, B., (1966) Diffusiophoresis of large aerosol particles, Journal of Colloid and Interface Science 22(2): 117-125, http://dx.doi.org/10.1016/0021-9797(66)90072-5

[27] Back, G., Beyler, C., Dinenno, P., and Tatem, P., (1994) Wall Incident Heat Flux Distributions Resulting from an Adjacent Fire, Fire Safety Science 4: 241-252, http://dx.doi.org/10.3801/IAFSS.FSS.4-241. 